Published in final edited form as:

Curr Opin Pediatr. 2016 June ; 28(3): 294-297. doi:10.1097/MOP.0000000000000340.

\title{
Anaphylaxis in Children
}

\author{
Karen S. Farbman, MD, MPH ${ }^{1}$ and Kenneth A. Michelson, MD 1 \\ ${ }^{1}$ Boston Children's Hospital, Division of Emergency Medicine, Boston, MA
}

\section{Abstract}

Purpose of review-Anaphylaxis is a serious allergic reaction that can be life threatening. We will review the most recent evidence regarding the diagnosis, treatment, monitoring, and prevention of anaphylaxis in children.

Recent Findings-Histamine and tryptase are not sufficiently accurate for routine diagnosis of anaphylaxis, so providers should continue to rely on clinical signs. Platelet-activating factor shows some promise in the diagnosis of anaphylaxis. Intramuscular is the best route for epinephrine administration for children of all weights. Glucocorticoids may reduce prolonged hospitalizations for anaphylaxis. Children with anaphylaxis who have resolving symptoms and no history of asthma or previous biphasic reactions may be observed for as few as 3-4 hours before emergency department discharge. Early peanut introduction reduces the risk of peanut allergy.

Summary-Epinephrine remains the mainstay of anaphylaxis treatment, and adjuvant medications should not be used in its place. All patients with anaphylaxis should be prescribed and trained to use an epinephrine autoinjector. Clinically important biphasic reactions are rare. Observation in the emergency department for most anaphylaxis patients is recommended, with duration determined by risk factors. Admission is reserved for patients with unimproved or worsening symptoms, or prior biphasic reaction.

\section{Keywords}

Anaphylaxis; allergic reaction; pediatric emergency medicine; allergy

\section{INTRODUCTION}

Anaphylaxis is a serious, rapid-onset allergic reaction that in rare cases causes death.[1] Recent evidence demonstrates that pediatric emergency department (ED) visits for children with anaphylaxis increased from 5.7 to 11.7 per 10,000 visits from 2009 to 2013, and that the overall burden of childhood allergic disease is increasing.[2,3] This highlights the need for providers and the lay public to have a heightened awareness for a diagnosis that has been under-recognized and undertreated. In 2010 the National Institute of Allergy, Immunology, and Infectious Diseases (NIAID) published its comprehensive guideline for managing food allergy.[4] The presence of any one of the following indicates that anaphylaxis is likely:

Corresponding Author Karen S. Farbman, MD, MPH, Division of Emergency Medicine, BCH 3066, Boston Children's Hospital, 300 Longwood Ave., Boston, MA 02115, Tel: (617) 355-6624, Fax: (617) 730-1024, karen.farbman@ @hildrens.harvard.edu. 
1) Acute hives or angioedema along with either respiratory symptoms or hypotension

2) Rapid occurrence of at least two of these signs after an exposure to a likely antigen:
a. Hives or angioedema
b. Respiratory symptoms
c. Hypotension
d. Gastrointestinal symptoms

3) Hypotension after exposure to a known allergen

The NIAID definition serves to alert the provider to the various presentations that anaphylaxis may have, and directs the provider to keep a high level of suspicion for anaphylaxis and the need for timely treatment.

We will highlight recent advances in the general care of patients with anaphylaxis. We will review updates on diagnostic testing, treatment with epinephrine and adjuvant medications, the reduced worry for fatal biphasic reactions, and the nuanced approach to the length of ED observation prior to discharge. Review of fluid resuscitation and airway support for anaphylactic shock are beyond the scope of this article.

\section{DIAGNOSTIC TESTING}

Histamine, platelet-activating factor (PAF), and tryptase have shown promise for diagnosing anaphylaxis. Although histamine likely does not have the ability to discriminate between anaphylactic and non-anaphylactic allergic reactions, tryptase may be useful if a patientspecific basal tryptase level is available.[5,6] Most promisingly, PAF was elevated in $20 \%$ of patients with cutaneous-only allergic reactions, in $67 \%$ of anaphylactic reactions without hypotension or serious respiratory involvement, and in $100 \%$ of patients with those severe anaphylactic signs.[5] This suggests a role for PAF in unclear or severe cases. PAF is likely involved in the pathogenesis of anaphylaxis.[7] Future clinical research could focus on the prognostic features of PAF. We do not commonly obtain diagnostic testing in patients with allergic symptoms in order to establish a diagnosis of anaphylaxis.

\section{EPINEPHRINE}

Intramuscular (IM) epinephrine delivered to the anterolateral thigh is the mainstay of therapy for anaphylaxis. Its vasoconstrictive alpha- 1 adrenergic effects treat shock and decrease airway edema; its mast cell stabilization activity decreases histamine release; and its beta- 2 adrenergic effects cause bronchodilation.[*8] Epinephrine should always be used as first line treatment for anaphylaxis, as supported by epidemiological data, animal studies, data on mechanism of action, and consensus opinions based on years of clinical experience. $[9,10]$ Delay in epinephrine delivery is associated with a higher risk of fatal anaphylaxis. $[9,11]$ In a large series of fatal cases, only 21 of 92 patients received epinephrine before cardiac arrest.[10] 
The dose of epinephrine for anaphylaxis is $0.01 \mathrm{mg} / \mathrm{kg}$, given IM with the $1: 1000$ concentration. [4] It can be drawn up via syringe, or given by epinephrine auto injector (EAI). Intravenous (IV) epinephrine is avoided due to the risk of dysrhythmia, except when a continuous infusion is needed for refractory, severe cardiorespiratory disease.

EAIs are available in adult, $0.3 \mathrm{mg}$ devices for patients $225 \mathrm{~kg}$, or junior $0.15 \mathrm{mg}$ devices for children $<25 \mathrm{~kg}$. Although some have expressed concern for infants weighing less than $10 \mathrm{~kg}$ receiving the junior EAI, we and others believe the benefits outweigh the risks in otherwise healthy infants outside the hospital setting.[12] In the hospital, infants under $10 \mathrm{~kg}$ should receive weight-based epinephrine 1:1000 IM to best approach $0.01 \mathrm{mg} / \mathrm{kg}$. Potential common adverse effects include jitteriness, pallor, and anxiety after administration of doses higher than $0.01 \mathrm{mg} / \mathrm{kg}$, and the concern for injecting the EAI into bone.[13] The discharge process should always include careful teaching on EAI use to avoid misuse.[14] Lack of improvement or worsening symptoms should prompt repeat epinephrine, which can be administered IM up to every 5-15 minutes, or as an IV infusion.[*15]

\section{ADJUVANT MEDICATIONS}

The 2010 NIAID guidelines acknowledged a lack of evidence to support glucocorticoids and antihistamines as routine medications used to treat anaphylaxis.[4] Nevertheless, this national consensus guideline recommends these medications in the ED setting. Glucocorticoids are well-established for asthma and airway edema.[16,17] A recent study showed a reduced risk of prolonged hospitalization among children hospitalized for anaphylaxis who received glucocorticoids.[18] However, glucocorticoids did not significantly reduce the risk of relapse in adults with anaphylaxis.[19] In the absence of a clinical trial to guide decision-making, we believe steroids should be given in the ED as adjuvant treatment, especially to patients with asthma or airway edema. Evidence to guide outpatient use of glucocorticoids is sparse, but 48-72 hours of continuing treatment based on the time window of biphasic reactions is typical.

While histamine-1 (H1) blockers such as diphenhydramine can reduce urticaria, they do not impact the underlying pathophysiology of anaphylaxis, and therefore have no role as a substitute for epinephrine. Controlled trials of H1 blockers are unlikely in anaphylaxis. We believe it is reasonable to give antihistamines in the ED as adjuvant treatment to improve comfort, especially to patients with urticaria or angioedema. The role of histamine-2 blockers such as ranitidine is also unclear but has efficacy for adults with urticaria.[20] No studies have specifically assessed their efficacy for treating anaphylaxis.[21] Therefore, we believe that routine use is unnecessary.

\section{BIPHASIC REACTIONS}

A 6-fold increase in anaphylaxis hospitalizations with stable mortality rates ( 0.047 cases per 100,000 population) was observed over the past twenty years.[22] This may be due to rising concern that many patients with anaphylaxis are at risk for biphasic reactions, a late recrudescence of anaphylaxis. However, the incidence of clinically important biphasic reactions is low. In children, past evidence suggested a rate of biphasic reactions as high as 
$20 \%$, but recent data suggest it is much lower.[23,24] Among adults, the strongest recent evidence shows a $1-4 \%$ rate of biphasic reactions, with most occurring within eight hours. $[25,26, * 27]$

\section{MONITORING AND DISPOSITION}

The most recent ED practice parameter for anaphylaxis recommends providers "strongly consider observing patients who have experienced anaphylaxis for at least 4 to 8 hours and observe patients with a history of risk factors for severe anaphylaxis for a longer period."

[15] Risk factors include asthma, previous biphasic or protracted anaphylaxis, repeat doses of epinephrine, wheezing, hypotension, or pharyngeal edema.[25]

Because signs and symptoms of anaphylaxis can return as epinephrine is metabolized, it is prudent to observe all patients for at least 3-4 hours in the ED after administration of epinephrine. We believe institutions should adopt clinical practice guidelines to reduce observation periods in low-risk patients, and we propose one candidate guideline (table).

\section{PREVENTION OF ANAPHYLAXIS}

The prevalence of anaphylaxis has increased over the past fifteen years.[2,3] This is likely related to an increase in food allergy: peanut allergies have tripled in the past 10-15 years and now affect 1 in 50 children.[28] In the 2015 LEAP trial, high-risk infants between 4-11 months of age who were randomized to peanut avoidance had a significantly higher prevalence $(13.7 \%$ versus $1.9 \%)$ of peanut allergy at 5 years of age than those randomized to peanut consumption.[28,**29] This provides strong evidence in favor of early initiation of peanut to atopic children and raises the possibility that similar strategies could be effective for other foods or for the general population.

\section{ALLERGY ACTION PLAN}

Allergists and primary care providers should provide any patient with allergic reactions or anaphylaxis an individualized allergy action plan. This allergy action plan will direct a patient to administer an EAI if signs and symptoms of anaphylaxis present.

\section{CONCLUSION}

The prevalence of allergic disease is increasing and warrants providers being current on management of anaphylaxis in order to prevent morbidity and mortality. Epinephrine is the first line therapy to treat anaphylaxis, and EAIs should be utilized by caretakers and field providers. Adjuvant therapies may be helpful, and we routinely use glucocorticoids and histamine-1 blockers. We recommend monitoring patients for no longer than 3-4 hours after epinephrine in low risk patients who have rapid symptom resolution. Future research should focus on the effectiveness of adjuvant medications, clarifying which subpopulations of patients are at risk for biphasic reaction, and identifying foods other than peanut for which early sensitization would prevent allergy. 


\section{ACKNOWLEDGEMENTS}

We would like to thank Dr. Anne Stack for her assistance with the study.

\section{FINANCIAL SUPPORT AND SPONSORSHIP}

Dr. Michelson is supported by grant number T32HS000063 from the Agency for Healthcare Research and Quality. The content is solely the responsibility of the authors and does not necessarily represent the official views of the Agency for Healthcare Research and Quality.

\section{REFERENCES}

1. Sampson HA, Munoz-Furlong A, Campbell RL, et al. Second symposium on the definition and management of anaphylaxis: summary report-second National Institute of Allergy and Infectious Disease/Food Allergy and Anaphylaxis Network symposium. J Allergy Clin Immunol. 2006; 117:391-397. [PubMed: 16461139]

2. Michelson KA, Monuteaux MC, Neuman MI. Variation and trends in anaphylaxis care in United States children's hospitals. Acad Emerg Med. Forthcoming. 2015

3. Jackson KD, Howie LD, Akinbami LJ. Trends in allergic conditions among children: United States, 1997-2011. NCHS Data Brief. 2013; 121:1-8. [PubMed: 23742874]

4. Burks AW, Jones SM, Boyce JA, et al. NIAID-sponsored 2010 guidelines for managing food allergy: Applications in the pediatric population. Pediatrics. 2011; 128:955-63. [PubMed: 21987705]

5. Vadas P, Perelman B, Liss G. Platelet-activating factor, histamine, and tryptase levels in human anaphylaxis. J Allergy Clin Immunol. 2013; 131:144-9. [PubMed: 23040367]

6. Borer-Reinhold M, Haeberli G, Bitzenhofer M, et al. An increase in serum tryptase even below 11.4 $\mathrm{ng} / \mathrm{mL}$ may indicate a mast cell-mediated hypersensitivity reaction: a prospective study in Hymenoptera venom allergic patients. Clin Exp Allergy. 2011; 41:1777-83. [PubMed: 22092437]

7. Gill P, Jindal NL, Jagdis A, Vadas P. Platelets in the immune response: Revisiting platelet-activating factor in anaphylaxis. J Allergy Clin Immunol. 2015; 135:1424-32. [PubMed: 26051949]

8*. Simons FE, Ebisawa M, Sanchez-Borges M, Thong BY, et al. 2015 update of the evidence base: World allergy organization anaphylaxis guidelines. World Allergy Organ J. 2015; 8:32. [PubMed: 26525001] [Global advances in epidemiology, diagnosis, and management along with patient factors are updated in this World Allergy Organization evidence update on anaphylaxis.]

9. Halbrich M, Mack D, Carr S, et al. CSACI position statement: Epinephrine auto-injectors and children < 15 kg. Allergy Asthma Clin Immunol. 2015; 11:20. doi:10.1186/s13223-015-0086-9. [PubMed: 26131015]

10. Sheikh A, Shehata YA, Brown SGA, Simons FE. Adrenaline for the treatment of anaphylaxis: Cochrane systematic review. Allergy. 2009; 64:204-12. [PubMed: 19178399]

11. Sampson HA, Mendelson L, Rosen JP. Fatal and near fatal anaphylactic reactions to food in children and adolescents. N Engl J Med. 1992; 327:380-84. [PubMed: 1294076]

12. Simons FE, Chan ES, Gu X, Simons KJ. Epinephrine for the out-of-hospital treatment of anaphylaxis in infants: is the ampule/syringe/needle method practical? J Allergy Clin Immunol. 2001; 108:1040-4. [PubMed: 11742286]

13. Kim L, Nevis I, Tsai G, et al. Children $<15 \mathrm{~kg}$ with food allergy may be at risk of having epinephrine auto-injectors administered into bone. Allergy Asthma Clin Immunol. 2010; 10:40. [PubMed: 25110478]

14. Sicherer SH, Forman JA, Noone SA. Use assessment of self-administered epinephrine among food-allergic children and pediatricians. Pediatrics. 2000; 105:359-62. [PubMed: 10654956]

15*. Campell RL, Li JT, Nicklas RA, et al. Emergency department diagnosis and treatment of anaphylaxis: a practice parameter. Ann Allergy Asthma Immunol. 2014; 113:599-608. [PubMed: 25466802] [This comprehensive emergency department based practice parameter creates summary statements, presents an algorithm to guide care, and grades the evidence behind each recommendation regarding adult emergency care of patients with anaphylaxis.] 
16. Rowe BH, Spooner CH, Ducharme FM, et al. Corticosteroids for preventing relapse following acute exacerbations of asthma. Cochrane Database Syst Rev. 2007:CD000195. [PubMed: 17636617]

17. Russell KF, Liang Y, O'Gorman K, et al. Glucocorticoids for croup. Cochrane Database Syst Rev. 2011:CD001955. [PubMed: 21249651]

18. Michelson KA, Monuteaux MC, Neuman MI. Glucocorticoids and hospital length of stay for children with anaphylaxis: A retrospective study. J Pediatr. 2015; 167:719-24. [PubMed: 26095285]

19. Grunau BE, Wiens MO, Rowe BH, et al. Emergency department corticosteroid use for allergy or anaphylaxis is not associated with decreased relapses. Ann Emerg Med. 2015; 66:381-9. [PubMed: 25820033]

20. Lin RY, Curry A, Pesola GR, et al. Improved outcomes in patients with acute allergic syndromes who are treated with combined H1 and H2 antagonists. Ann Emerg Med. 2000; 36:462-8. [PubMed: 11054200]

21. Nurmatov UB, Rhatigan E, Simons FE, Sheikh A. H2-Antihistamines for the treatment of anaphylaxis with and without Shock: a systematic review. Ann Allergy Asthma Immunol. 2014; 112:126-131. [PubMed: 24468252]

22. Turner PJ, Gowland MH, Sharma V, et al. Increase in anaphylaxis-related hospitalizations but no increase in fatalities: An analysis of United Kingdom national anaphylaxis data, 1992-2012. J Allergy Clin Immunol. 2015; 135:956-63. [PubMed: 25468198]

23. Lee JM, Greenes DS. Biphasic anaphylactic reactions in pediatrics. Pediatrics. 2000; 106:762-6. [PubMed: 11015520]

24. Lee J, Garrett JP, Brown-Whitehorn T, Spergel JM. Biphasic reactions in children undergoing oral food challenges. Allergy Asthma Proc. May-Jun. 2013; 34:220-6. [PubMed: 23676570]

25. Lee S, Bellolio F, Hess EP, Campbell RL. Predictors of biphasic reactions in the emergency department for patients with anaphylaxis. J Allergy Clin Immunol Pract. 2014; 2:281-87. [PubMed: 24811018]

26. Rohacek M, Edenhofer H, Bircher A, Bingisser R. Biphasic anaphylactic reactions: occurrence and mortality. Allergy. 2014; 69:791-97. [PubMed: 24725226]

27*. Grunau BE, Li J, Yi TW, et al. Incidence of clincially important biphasic reactions in emergency department patients with allergic reactions or anaphylaxis. Ann Emerg Med. 2014; 63:736-44. [PubMed: 24239340] [This retrospective study of 2,819 adult patients with anaphylaxis/allergic reaction found only five cases of clinically important biphasic reactions, and no fatalities. The authors conclude that prolonged routine monitoring of patients whose anaphylactic symptoms have resolved is likely unnecessary for patient safety.]

28. Fleischer DM, Sicherer S, Greenhawt M, et al. Consensus communication on early peanut introduction and the prevention of peanut allergy in high-risk infants. Pediatrics. 2015; 136:600-4.

29**. Du Toit G, Roberts G, Sayre PH, et al. Randomized trial of peanut consumption in infants at risk for peanut allergy. N Engl J Med. 2015; 372:803-13. [PubMed: 25705822] [Atopic infants randomized at age $4-11$ months to peanut avoidance had a higher $(13.7 \%)$ peanut allergy prevalence at age 60 months than those randomized to consume peanut $(1.9 \%)$. This indicates that pediatricians should recommend against peanut avoidance in atopic infants.] 


\section{KEY POINTS}

1. Clinically important biphasic reactions are rare in children with anaphylaxis

2. No adjuvant medication has been shown to ablate the pathophysiology of anaphylaxis, but consensus guidelines recommend the use of glucocorticoids and $\mathrm{H} 1$ blockers

3. Routine hospitalization is unnecessary for most children with anaphylaxis

4. Early introduction of peanuts prevents peanut allergy in atopic children 
TABLE

\begin{tabular}{|c|c|c|c|}
\hline Severity of Presentation & Symptoms, Signs, and Risk Factors & Monitoring Period & Discharge Criteria \\
\hline High & $\begin{array}{l}\text { Any of the following: } \\
\text { - Previous protracted or biphasic anaphylaxis } \\
\text { - Two or more doses of epinephrine } \\
\text { administered } \\
\text { - Moderate to severe wheezing on } \\
\text { presentation } \\
\text { - Hypotension } \\
\text { - Pharyngeal edema } \\
\text { - Persistence of symptoms without } \\
\text { improvement } \\
\text { - Worsening of symptoms }\end{array}$ & $\begin{array}{l}\text { Hospitalization for } 24 \text { or } \\
\text { more hours }\end{array}$ & $\begin{array}{l}\text { - Resolution of symptoms } \\
\text { - Epinephrine teaching completed } \\
\text { - Epinephrine autoinjector prescribed } \\
\text { - Able to access medical care }\end{array}$ \\
\hline Medium & $\begin{array}{l}\text { Any of the following: } \\
\text { - History of asthma } \\
\text { - Mild wheezing on presentation } \\
\text { - Slowly resolving symptoms }\end{array}$ & $\begin{array}{l}\text { 6-8 hours from } \\
\text { epinephrine dose }\end{array}$ & $\begin{array}{l}\text { - Resolution of symptoms } \\
\text { - Epinephrine teaching completed } \\
\text { - Epinephrine autoinjector prescribed } \\
\text { - Able to access medical care }\end{array}$ \\
\hline Low & $\begin{array}{l}\text { All of the following: } \\
\text { - Asymptomatic shortly after administration } \\
\text { of epinephrine } \\
\text { - No other risk factors }\end{array}$ & $\begin{array}{l}\text { 3-4 hours from } \\
\text { epinephrine dose }\end{array}$ & $\begin{array}{l}\text { - Resolution of symptoms } \\
\text { - Epinephrine teaching completed } \\
\text { - Epinephrine autoinjector prescribed } \\
\text { - Able to access medical care }\end{array}$ \\
\hline
\end{tabular}

Candidate framework for determining the period of monitoring for children with anaphylaxis. 